\title{
Bit Error Ratio, Caused by Doppler Effect, for Systems of Space Diversity Reception
}

\author{
Mikhail G. Polyak* \\ Academician M.F. Reshetnev Information Satellite Systems \\ 52 Lenin Str., Zheleznogorsk, 662972, Russia
}

Received 21.06.2018, received in revised form 13.07.2018, accepted 16.07.2018

Today digital data transmission plays a leading role for satellite systems. However, digital data transmission is possible with errors at demodulation, which cause distortion of transmitting information. Errors of digital data transmission are due to three causes. First cause is a low level of signal to noise ratio. Second cause is Doppler Effect. Third cause is symbol-to-symbol interference conditional multipath propagation. Space diversity reception is effective method of bit error resistance.

Doppler Effect is the most significant for bit error probability at satellite communication. Because satellite move very fast in cosmic space. This article show effective of space diversity reception for decrease of bit error probability, which caused by Doppler Effect.

Keywords: satellite communications, bit error ratio, Doppler Effect, space diversity reception.

Citation: Polyak M.G. Bit error ratio, caused by doppler effect, for systems of space diversity reception, J. Sib. Fed. Univ. Eng. technol., 2019, 12(1), 64-71. DOI: 10.17516/1999-494X-0075.

\section{Вероятность ошибки,}

вызванной явлением Доплера, в системах

пространственного разнесенного приема

\author{
М.Г. Поляк \\ АO «Информационные спутниковые системы» \\ имени академика М.Ф. Решетнева» \\ Россия, 662972, Железногорск, ул. Ленина, 52
}

Передача цифровой информации в спутниковых сетях играет в настоящее время ведущую роль. Однако передача иифровой информачии вследствие воздействия различных факторов может осуществляться с ошибками при демодуляции, которые приводят к искажению

(C) Siberian Federal University. All rights reserved

This work is licensed under a Creative Commons Attribution-NonCommercial 4.0 International License (CC BY-NC 4.0).

* Corresponding author E-mail address: mpolyak1502@gmail.com 
переданной информащии. Ошибки при передаче циифровой информащии возникают по трем причинам: падение уровня отношения сигнал/шум сигнала; действие эффекта Доплера, ввиду межсимвольной интерференции, возникающей по причине многолучевого распространения сигнала. Эффективным методом борьбы с ошибками при приеме ичифровых сигналов признан разнесенный прием сигнала.

В связи с космическими объектами одним из наиболее важных факторов, влияющих на вероятность ошибки, является доплеровское смещение частоты, вызванное движением космического аппарата. В данной статье показана эффективность разнесенного приема с точки зрения снижения вероятности ошибки на один бит, возникающей вследствие эффекта Доплера.

Ключевые слова: спутниковая связь, вероятность очибки на бит, эффект Доплера, пространственный разнесенный прием радиосигналов.

\section{Introduction}

Today digital data transmission plays a leading role for satellite systems. Digital signals are very popular, because they allow transmit information more precisely and faster than analog signals. However, digital data transmission is possible with errors at demodulation, which cause distortion of transmitting information.

Modern digital data transmission systems have to provide bit error ratio (BER) not less than $10^{-5}$. So special algorithms for processing signals and coding are often using today.

Errors of digital data transmission are due to three causes. First cause is a low level of signal to noise ratio (SNR), when signal transmit through noisy or fading communication channel. Second cause is Doppler Effect. Third cause is symbol-to-symbol interference conditional multipath propagation. Space diversity reception is effective method of bit error resistance.

Doppler Effect is the most significant for bit error probability at satellite communication. Because satellite move very fast in cosmic space. This article show effective of space diversity reception for decrease of bit error probability, which caused by Doppler Effect.

\section{Influence of Doppler Effect on bit error ratio for systems of one and two antennas reception}

Doppler effect is very significant for BER especially for low-orbiting satellite systems. For example, if satellite rotates on $700 \mathrm{~km}$ circular orbit, then its speed is near $7.5 \mathrm{~km} / \mathrm{s}$. Time appearance of these satellites is very limited. Satellite's speed is maximal when satellite to turn up horizon. In this moment its Doppler translation is ultimate. If signal frequency is $1.6 \mathrm{GHz}$, then maximum Doppler translation is near $7 \mathrm{kHz}$. Thus signal spectrum shift from nominal value. Nominal value of frequency is generated local heterodyne. Demodulation errors eventuate, in view of the fact that carrier received signal frequency is not equal nominal frequency of local heterodyne.

Today systems of automatic frequency control are very popular for decrease BER caused by Doppler effect. But these systems have lags, which forbid completely except errors. Space diversity reception allow except errors especially when Doppler translation is small. In this case diversity reception allows decrease error probability in two degrees. For example, BER may be decrease from $10^{-8}$ to $10^{-16}$, sub verbo.

BER, caused by Doppler effect, for DBPSK evaluate by using formula [1-3]:

$$
-65-
$$




$$
P=\frac{\rho_{0} \cdot\left(1-J_{0}\left(2 \cdot \pi \cdot f_{d} \cdot T\right)\right)}{2 \cdot\left(\rho_{0}+1\right)},
$$

here $\rho_{0}$ - mean SNR; $f_{d}[\mathrm{~Hz}]$ - maximum value of Doppler frequency shift; $J_{0}\left(2 \cdot \pi \cdot f_{d} \cdot T\right)$ - correlation function in-phased and antiphased components of complex process shifted on $\mathrm{T}$, which is in Gaussian channel. Correlation function is nought-order Bessel function [4]; T [s] - bit duration and delay period of demodulation DBPSK signal.

Diversity reception may be in frequency, in polarization, in angel, in time and in space $[1,5]$. Frequency diversity reception and time diversity reception apply for navigation systems, but it require additional frequency band or limit amount of transmitted information. Polarization diversity reception requires two received antennas or have additional loss on $3 \mathrm{~dB}$. Space diversity reception is more beneficent and efficient method of diversity reception. Signals from different diversities antennas are not correlated if between antennas distance is near several wave length.

BER, caused by Doppler effect, for two antennas reception of DBPSK signals evaluate by using formula [1-3]:

$$
P=0,25 \cdot\left[1-J_{0}\left(2 \cdot \pi \cdot f_{d} \cdot T\right)\right]^{2} \cdot\left[2+J_{0}\left(2 \cdot \pi \cdot f_{d} \cdot T\right)\right] .
$$

Fig. 1 demonstrated block diagram of one antenna DBPSK receiver. Fig. 2 demonstrated block diagram of two antennas DBPSK receiver $[1,5]$.

Research influence of Doppler effect on BER with a different value of Doppler translation and information rate.

\section{Research of influence of Doppler effect on bit error ratio}

Plot graph of dependence BER from Doppler translation. In case SNR equal 10, information rate equal $32 \mathrm{~kb} / \mathrm{s}$ and $32 \mathrm{mb} / \mathrm{s}$.

Carry out analyze of obtained dependence. In case small Doppler translation space diversity reception allow decrease error probability in two degreases from $10^{-8}$ to $10^{-16}$. However if value of

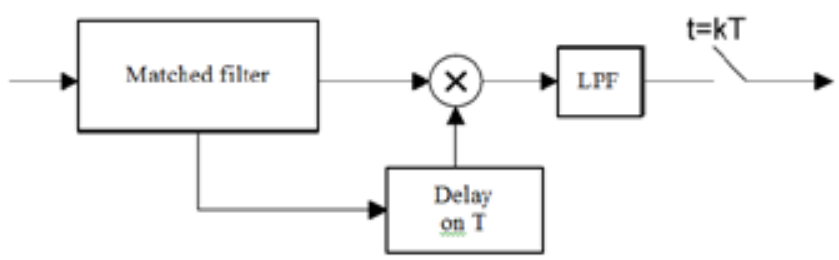

Fig. 1. Block diagram of one antenna DBPSK receiver

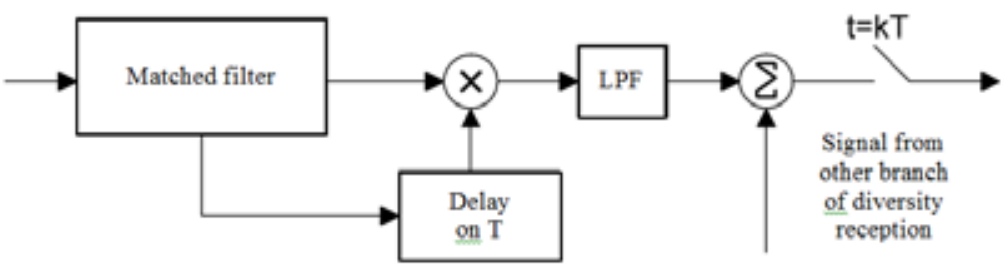

Fig. 2. Block diagram of two antennas DBPSK receiver

$$
-66-
$$




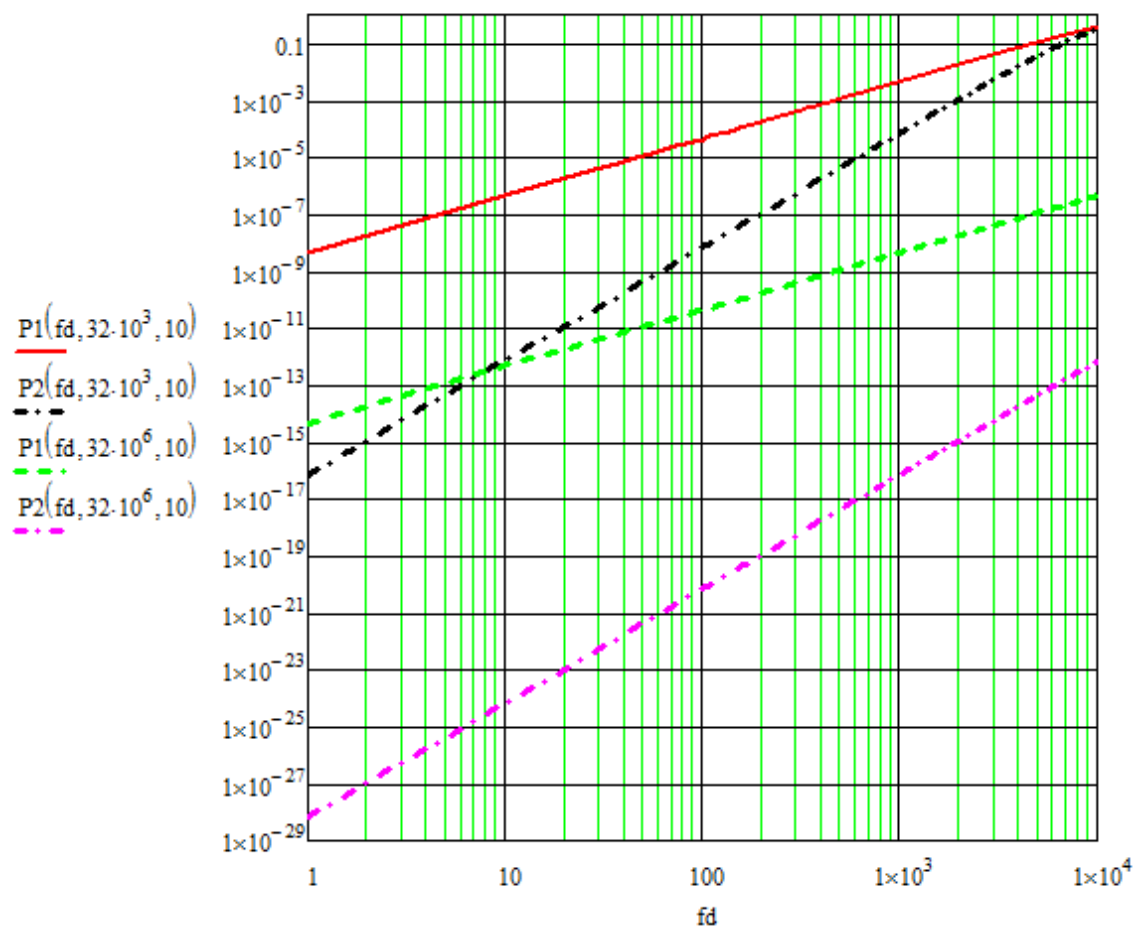

Fig. 3. Dependence bit error ratio from Doppler translation

Doppler translation will be increased, then efficiency of diversity reception will be decreased. For example, in case value of Doppler translation equal $1 \mathrm{kHz}$ and information rate equal $32 \mathrm{~kb} / \mathrm{s}$ BER will be decreased less in two degrees; and if value of Doppler translation equal $7 \mathrm{kHz}$ BER will be decreased in 1.5. Besides, the faster information rate got the smaller BER, caused by Doppler effect. For example, in case one antenna receiving for information rate $32 \mathrm{~kb} / \mathrm{s}$ and $32 \mathrm{mb} / \mathrm{s}$ BER decrease on 6 degreases, and in case two antennas receiving for information rate $32 \mathrm{~kb} / \mathrm{s}$ and $32 \mathrm{mb} / \mathrm{s}$ BER decrease on 12 degreases.

\section{Averaging of influence of Doppler effect on bit error ratio for receiving low-orbiting satellite's signals}

For research efficiency of space diversity reception going to average influence of Doppler effect with different information rates. Going to average of momentary value of Doppler translation.

Value of Doppler translation:

$$
f_{d}=\frac{v_{r}}{\lambda}
$$

here $\lambda=\frac{c}{f}[\mathrm{~m}]-$ wave length; $\mathrm{c}[\mathrm{m} / \mathrm{s}]-$ light speed; $v_{r}[\mathrm{~m} / \mathrm{s}]-$ radial velocity of satellite to land.

Research momentary value of radial velocity of satellite to land using Fig. 4.

Duration of communication session depend from duration time of line of sight of satellite on horizon line. Radial velocity of satellite is maximal at the moment of satellite appearance. Radial velocity of satellite equal nought at the moment of flight vertical relative to land obtainer (dot "O").

$$
-67-
$$




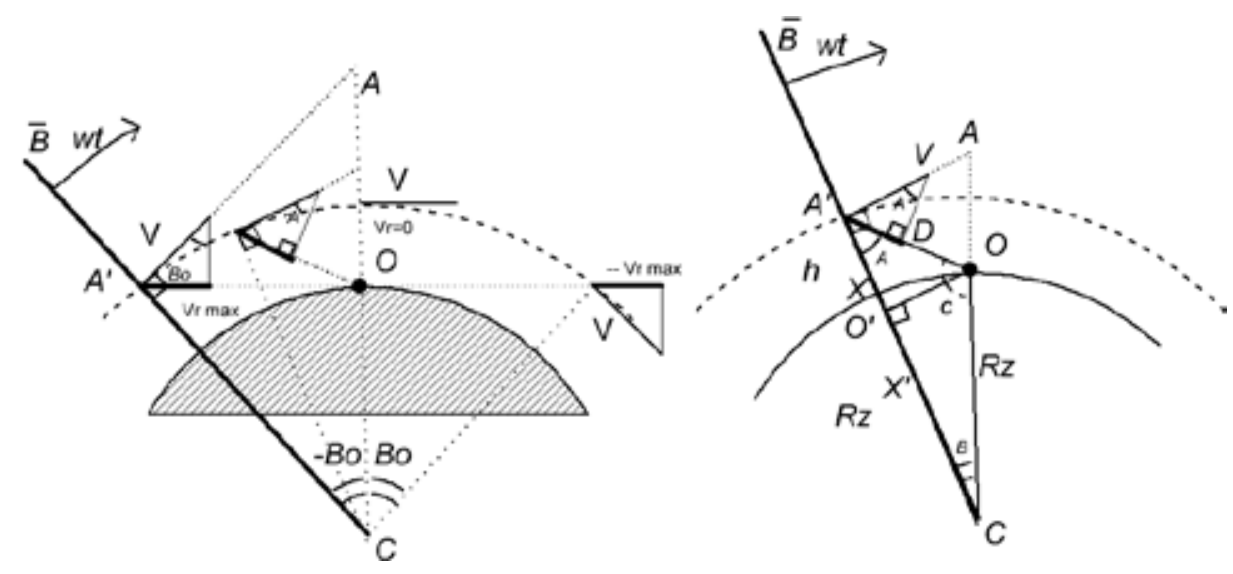

Fig. 4. Research of momentary value of radial velocity

Angle and duration time of line of sight of satellite on horizon line depend from satellite orbit height [6]:

$$
\beta_{0}=\arccos \frac{R z \cdot \cos \left(\alpha_{\min }\right)}{R z+h}-\alpha_{\min }
$$

here $R z=6371[\mathrm{~km}]-$ earth radius; $h=700[\mathrm{~km}]$ - satellite orbit height; $\alpha_{\min }[\mathrm{rad}]-$ minimal operating angle.

$$
\Delta t=\frac{2 \cdot \beta_{0}}{\omega}
$$

here $\omega=\frac{V}{R z+h}[\mathrm{rad} / \mathrm{s}]-$ angular velocity of satellite motion.

Orbital velocity of satellite motion $[\mathrm{km} / \mathrm{s}]$ :

$$
V=\sqrt{\frac{G \cdot M z}{R z+h}}=7,523,
$$

here $M z=5,972 \cdot 10^{24}[\mathrm{~kg}]$ - earth mass; $G=6,67 \cdot 10^{-11}\left[\mathrm{~m}^{3} \mathrm{~kg}^{-1} \mathrm{~s}^{-2}\right]$ - gravitation constant.

In accord Fig. 4 moment value of radial velocity of satellite motion define by angle $A$. Which is angle between vertical line and satellite direction.

$$
v_{r}=V \cdot \sin (A),
$$

Get analytical dependence for define angle $A$ from that:

1) Direction of satellite velocity is perpendicular for direction to earth center (point $C$ ) $\angle \mathrm{AA}^{\prime} \mathrm{C}=\pi / 2$;

2) Direction from earth center to satellite (vector $B$ ) have uniform angular velocity;

3) Angle $B$ move from $-\beta_{0}$ to $\beta_{0}$.

Initiate reasoning:

1) Angle $A$ belong to triangle $\mathrm{A}^{\prime} \mathrm{VD}$, when $\angle \mathrm{VA}^{\prime} \mathrm{D}=\pi / 2-A$. 
2) Angle $\angle \mathrm{AA}^{\prime} \mathrm{C}=\pi / 2$ consist from angles $\angle \mathrm{VA}^{\prime} \mathrm{D}+\angle \mathrm{CA}^{\prime} \mathrm{D}$. Result from that $\angle \mathrm{CA}^{\prime} \mathrm{D}=\pi / 2-\angle \mathrm{VA}^{\prime} \mathrm{D}=\pi / 2-\pi / 2+A=A$.

3) Define angle $A=\angle \mathrm{CA}^{\prime} \mathrm{D}=\angle \mathrm{CA}^{\prime} \mathrm{O}$ dependence from angle $B=-B_{0}+\omega t$.

4) We know two sides $C^{\prime} A^{\prime}, C O$ of triangle $C^{\prime} A^{\prime} O$ and angle between their sides $B=\angle A^{\prime} C O$. Therefore definition of angle $A$ is possible. For that divide triangle on two right-angled triangles $\mathrm{CO}^{\prime} \mathrm{O}$ и $\mathrm{A}^{\prime} \mathrm{O}^{\prime} \mathrm{O}$ by plot perpendicular O'O.

5) Length of $\mathrm{O}^{\prime} \mathrm{O}$ depend from sine of angle $B: \mathrm{O}^{\prime} \mathrm{O}=R z \sin (B)=R z \sin \left(-B_{0}+\omega t\right)$.

6) Length of side CA' equal $R z+h$. Point $\mathrm{O}^{\prime}$ divide side CA' on two parts: A'O' having length $\mathrm{X}$ and CO' having length $X^{\prime}$. Side CO' depend from cosine of angle $B: X^{\prime}=R z \cos (B)=R z \cos \left(-B_{0}+\omega t\right)$.

7) Therefore $\mathrm{CO}^{\prime}=X=R z+h-X^{\prime}=R z+h-R z \cos \left(-B_{0}+\omega t\right)$.

8) Therefore angle $A=\angle \mathrm{O}^{\prime} \mathrm{A}^{\prime} \mathrm{O}$ define arctangent division side O'O on CO':

$$
A=\operatorname{arctg}\left[\frac{O^{\prime} O}{A^{\prime} O^{\prime}}\right]=\operatorname{arctg}\left[\frac{R z \cdot \sin \left(-B_{0}+\omega \cdot t\right)}{R z+h-R z \cdot \cos \left(-B_{0}+\omega \cdot t\right)}\right] .
$$

Use formulas (7) and (8) for definition of radial velocity of satellite motion subject to time. In view of the fact that additional Doppler frequency shift more nought, when satellite appear on horizon line, and $\sin \left(-B_{0}\right)$ less nought, work in multiply $(-1)$ :

$$
v_{r}(t)=V \cdot(-1) \cdot \sin \left[\operatorname{arctg}\left[\frac{R z \cdot \sin \left(-B_{0}+\omega \cdot t\right)}{R z+h-R z \cdot \cos \left(-B_{0}+\omega \cdot t\right)}\right]\right] .
$$

Plot the graph radial velocity of satellite dependence on time (9), using $\alpha_{\min }=3 \frac{\pi}{180}[\mathrm{rad}]$ and getting $\beta_{0}=0,399$ [rad], $\Delta t=750,41[\mathrm{~s}], \omega=1,064 \cdot 10^{-3}[\mathrm{rad} / \mathrm{s}]$.

Average of influence of Doppler effect on BER for session timeout by using formula (9). Average BER get as integral on formulas (1) or (2) according to one and two antennas, in place of Doppler frequency shift use formula (3), in place of radial velocity use formula (9), getting expression average to time:

$$
P 1=\frac{1}{\Delta t} \int_{0}^{\Delta t} \frac{\rho_{0} \cdot\left(1-J_{0}\left(2 \cdot \pi \cdot \frac{V \cdot(-1) \cdot \sin \left[\operatorname{arctg}\left[\frac{R z \cdot \sin \left(-B_{0}+\omega \cdot t\right)}{R z+h-R z \cdot \cos \left(-B_{0}+\omega \cdot t\right)}\right]\right]}{\lambda} \cdot T\right)\right.}{2 \cdot\left(\rho_{0}+1\right)} d t,
$$

$$
\begin{aligned}
P 2=\frac{1}{\Delta t} \int_{0}^{\Delta t}\left[1-J_{0}\left(2 \cdot \pi \cdot \frac{V \cdot(-1) \cdot \sin \left[\operatorname{arctg}\left[\frac{R z \cdot \sin \left(-B_{0}+\omega \cdot t\right)}{R z+h-R z \cdot \cos \left(-B_{0}+\omega \cdot t\right)}\right]\right]}{\lambda} \cdot T\right)\right. & {[]^{2} } \\
\cdot & {\left[2+J_{0}\left(2 \cdot \pi \cdot \frac{V \cdot(-1) \cdot \sin \left[\operatorname{arctg}\left[\frac{R z \cdot \sin \left(-B_{0}+\omega \cdot t\right)}{R z+h-R z \cdot \cos \left(-B_{0}+\omega \cdot t\right)}\right]\right]}{\lambda} \cdot T\right)\right] d t . }
\end{aligned}
$$




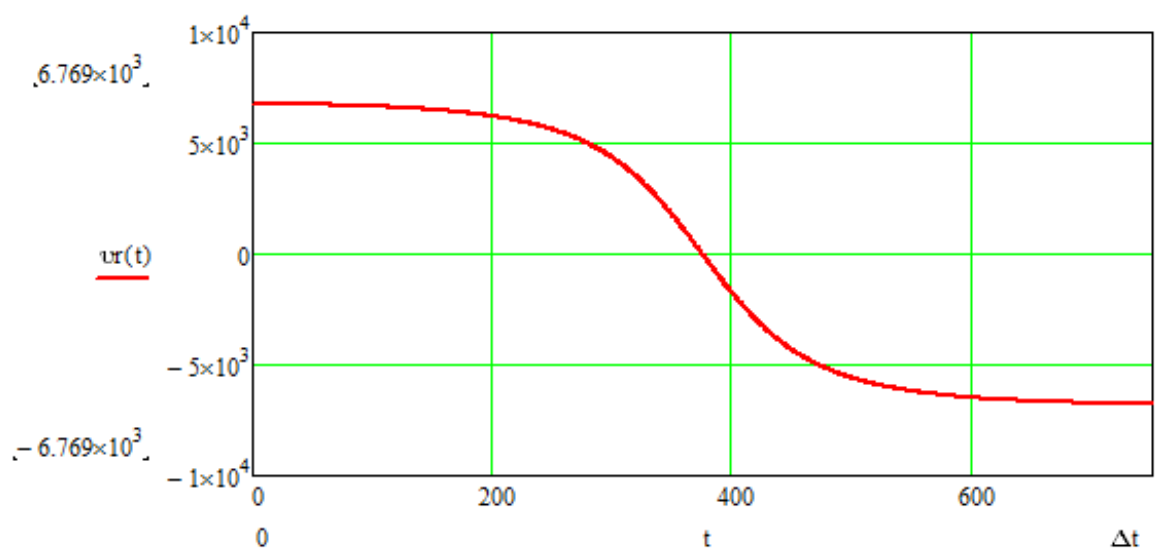

Fig. 5. The graph of the radial velocity of the satellite

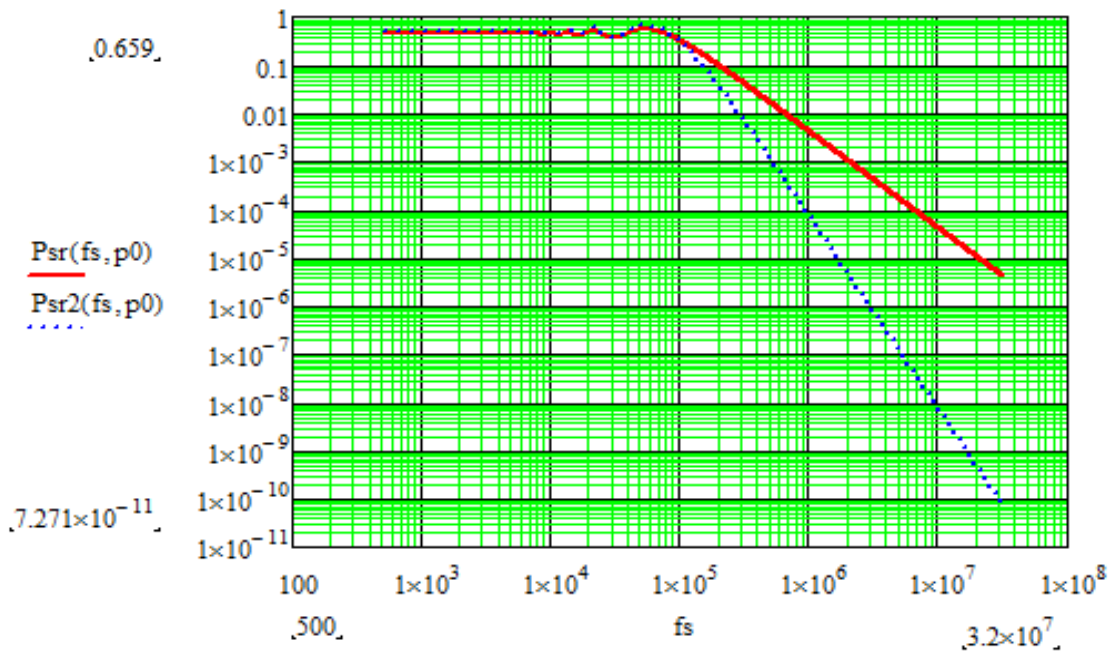

Fig. 6. Average bit error ratio dependence on information rate for one or two antennas receiving

Plot the graph average BER dependence on information rate $f_{S}=\frac{1}{T}$ on formulas (10), (11).

Carry out analyze of obtained dependence. In case information rate equal $1 \mathrm{mb} / \mathrm{s}$ space diversity reception allow decrease average BER in two degreases from $10^{-2}$ to $10^{-4}$. And in case information rate equal $32 \mathrm{mb} / \mathrm{s}$ space diversity reception allow decrease average BER in two degreases from $10^{-5}$ to $10^{-10}$.

\section{Summary and Conclusions}

Doppler effect increases number of errors at demodulation. In this paper consider efficiency of decreases number of errors at demodulation by using system of space diversity reception. For example of advantage was taken low-orbiting satellite communication system. Satellite orbit height was taken $700 \mathrm{~km}$, type of signal modulation was taken DBPSK. 
Fig. 3 was showing by using formula (1) and (2) that space diversity reception allow decrease BER in two degrees from $10^{-8}$ to $10^{-16}$ for small value of Doppler frequency shift. And if value of Doppler translation equal $7 \mathrm{kHz}$ BER will be decreased in 1.5 .

Besides in this paper was average influence of Doppler effect on BER for session timeout and was getting formulas (10) and (11). In case information rate equal $32 \mathrm{mb} / \mathrm{s}$ space diversity reception allow decrease average BER in two degreases from $10^{-5}$ to $10^{-10}$.

\section{References}

[1] William C. Jakes. Microwave mobile communications. 1974

[2] Voelker H.B. Phase-Shift Keying in Fading Channels, Proc. IEEE, 107, Part B, January 1960,31

[3] Bello P.A. and Nelin B.D. The Influence of Fading Spectrum on the Binary Error Probabilities of Incoherent and Differentially Coherent Matched Filter Receivers. IRE Trans. Comm, Systems, June 1962, 160-168.

[4] Rice S.O. Mahematical Analysis of Random Noise, Bell System Tech. J. 23, July 1944, 282332; 24, January 1945, 46-156.

[5] Rice S.O. Statistical Properies of a Sine Wave Plus Rendom Noise», Bell System Tech. J. 27, January 1948, 109-157.

[6] Bernard Sklar. Digital Communications. Fundamentals and Applications. Second edition.: Perevod s angliyskogo. Moscow: Izdatelskiy dom «Villiams», 2003. 1104.

[7] Бордовицына Т.В. Технологии глобального позиционирования (GPS / ГЛОНАCC). Электронное учебное пособие. Томск, 2007. [Bordovitsina T.V. Global Positioning Technology (GPS / GLONASS). E-learning tool Tomsk, 2007. (in Russian)] 